\title{
PERTANGGUNG JAWABAN PIDANA TERHADAP PELANGGARAN IZIN TINGGAL KEIMIGRASIAN OLEH MAHASISWA ASING DI INDONESIA
}

\author{
Endah Lestari Dwirokhmeiti dan Edwin Setyawan
}

This study aims to investigate the implementation of the Immigration Act the Government of the Republic of Indonesia No. 6 of 2011, which regulates the residence permit and to determine the response to criminal acts of abuse and residence permit immigration by foreign students in Indonesia.

This research method is implemented with the normative, where researchers conducted a literature study by way of examining the books, litertur, and legislation relating to matters that will be discussed in the thesis writer .

The findings obtained from this study include: (1) the implementation of the Law of the Republic of Indonesia No. 6 in 2011, with about handling abuse and violators of residency immigration has been running with the maximum, but there are several obstacles that occur within the system implementation of the completion of a issue a limited residence permit. (2) the response to the crime of abuse and violation of residence permit the immigration dilakuan judicial action submitted to the police and then processed through the court, and may be subject to criminal sanctions in accordance with the provisions of applicable law, or by administrative action. Immigration officials authorized to conduct immigration adminitratif actions against foreigners in Indonesia which could jeopardize the security and public order as described in Law No. 6 of 2011 on immigration.

Keywords: Abuse, Immigration, Foreign Students.

PENDAHULUAN

Imigrasi berasal dari kata kerja "migrate" atau kata benda "migration" (bahasa inggris), yang berarti " $g$ o from one country or place of residence to sattle in another". 'Jadi suatu migrasi adalah perpindahan manusia secara geografis, baik perorangan maupun secara berkelompok dari suatu tempat atau Negara asal ke tempat atau Negara lain dengan tujuan untuk menetap. Bahasa inggris memandang imigrasi dari dua aspek terhadap pengertian yang sama, yaitu imigrasi (tempat yang didatangi) dan emigrasi. Hukum keimigrasian merupakan bagian dari system hukum yang berlaku di Indonesia. Hukum Keimigrasian di Indonesia telah ada sejak pemerintahan kolonial Belanda. ${ }^{2}$ Ketentuan hukum keimigrasian di Indonesia sejak proklamasi kemerdekaan Indonesia tahun 1945 hingga tahun 1991 secara formal tidak mengalami perkembangan berarti sampai akhirnya pada tanggal 31 Maret 1992 diundangkan Undang-undang Nomor 9 Tahun 1992 tentang Keimigrasian.

Dikatakan demikian karena ketentuan keimigrasian masih tersebar dalam beberapa ketentuan perundang-undangan dan masih kuat dipengaruhi hukum kolonial. Di samping tidak sesuai lagi dengan perkembangan kehidupan nasional,

\footnotetext{
${ }^{1}$ Ajad Sudrajad Havid, Formalitas Keimigrasian, Direktorat Jenderal Imigrasi Departemen Hukum dan HAM thn 2008.hal 83

${ }^{2}$ M.Imam Santoso, "Perspektif Imigrasi dalam Pembangunan Ekonomi dan Ketahanan Nasional”, UI Press Jakarta, 2004.hal 24
} 
sebagian dari ketentuan tersebut masih merupakan ketentuan bentukan pemerintah kolonial.

Sebagian dari ketentuan tersebut sudah tidak dapat diterapkan dalam pelaksanaannya dikarenakan semakin berkembangnya global dewasa ini mendorong meningkatnya mobilitas penduduk dunia yang menimbulkan berbagai dampak, baik yang menguntungkan maupun yang merugikan kepentingan dan kehidupan bangsa dan Negara Republik Indonesia sehingga diperlukan peraturan perundang-undangan tentang Keimigrasian baru yang merupakan perwujudan penegakan hukum serta kedaulatan atas wilayah Indonesia dengan berbagai masalah keimigrasian yang baru sekarang ini, oleh karena itu pada tanggal 5 Mei 2011 diundangkan Undang-undang Republik Indonesia Nomor 6 Tahun 2011 tentang Keimigrasian menggantikan Undang-undang Republik Indonesia Nomor 9 tahun 1992 tentang Keimigrasian.

Dengan demikian peran penting aspek keimigrasian dalam tatanan kehidupan kenegaraan akan dapat terlihat dalam pengaturan masuk atau keluar orang dari dan ke dalam wilayah Indonesia, pemberian Tanda Masuk orang asing pada tempat pemeriksaan Imigrasi, dan pemberian izin tinggal Keimigrasian serta pengawasan terhadap orang asing selama berada di wilayah Indonesia dalam hal keberadaan dan kegiatan yang dilakukan orang asing sesuai dengan Visa atau Izin Tinggal Keimigrasian yang mereka gunakan di Indonesia.

\section{PEMBAHASAN}

\section{PROSEDUR PENGAWASAN TERHADAP MAHASISWA ASING YANG MASUK WILAYAH INDONESIA}

\section{Prosedur Izin Keimigrasian di Indonesia}

Setiap orang yang masuk atau keluar wilayah indonesia wajib memiliki surat perjalanan, dalam keimigrasian terdapat tata cara masuk dan keluar indonesia, baik dari warga negara asing maupun warga negara Indonesia.

\section{Prosedur Pengawasan Terhadap Orang Asing yang Datang dan Keluar Wilayah Indonesia}

Dalam menjaga keamanan negara keimigrasian melakukan pengawasan terhadap orang asing yang datang dan keluar wilayah indonesia maupun saat orang asing tersebut sudah masuk di wilayah indonesia.

\section{Pengasawan Orang Asing di Wilayah Indonesia}

\section{a. Pengawasan Administratif}

Pengawasan administratif adalah pengawasan yang dilakukan melalui penelitian surat-surat atau dokumen, berupa pencatatan, pengolahan data, dan penyajian maupun penyebaran informasi secara manual dan elektronik, tentang lalu lintas keberadaan dan kegiatan orang asing.

Pengawasan administratif dilakukan melalui pengumpulan, penelitian dan pemeriksaan terhadap surat-surat atau dokumen orang asing.

\section{b. Pengawasan Lapangan}


Pengawasan lapangan adalah pengawasan yang di lakukan berupa pemantauan, patroli, proses, dengan mengumpulan bahan keterangan, pencarian orang dan alat bukti yang berhubungan dengan tanda pengenal keimigrasian.

Pengawasan lapangan dapat dilakukan ditempat-tempat dimana beradanya orang asing, berupa alat angkut, perusahaan, hotel dan sejenisnya, pusat keramaian, serta tempat hiburan lainya. Agar tercipta kondisi yang tertib dalam keimigrasian, perlu di lakukan pengawasan yang berkesinambungan, agar tidak terkesan monoton dan hanya sekedar rutinitas tugas biasa, perlu ditempuh ditempuh upaya khusus atau operasi khusus yang bersifat insidentil, atau dengan kata lain, waktu pelaksanaan pengawasan lapangan secara rutin.

\section{Pelaksanaan Pengawasan dan Kewajiban Mahasiswa Asing Selama Berada di Wilayah Negara Indonesia \\ Prosedur bagi Warga Asing yang akan menjadi Mahasiswa pada Perguruan Tinggi di Indonesia. .}

Ada dua cara mahasiswa asing untuk belajar di Indonesia :

a) Masuk ke Wilayah Indonesia dengan Visa Tinggal terbatas

- Setiap pelajar atau mahasiswa asing yang belajar Indonesia harus dengan izin tinggal terbatas;

- Untuk mendapatkan izin tinggal terbatas,maka mahasiswa asing tersebut harus memiliki visa tinggal terbatas yang di keluarkan oleh Kedutaan Besar Republik Indonesia di luar negeri.

b) Alih status atau konversi dari izin tinggal kunjungan menjadi izin tinggal terbatas.

- Mahasiswa asing yang masuk kewilayah Indonesia dengan Visa kunjungan atau izin tinggal kunjungan dapat dialih statuskan menjadi izin tinggal terbatas, sepanjang telah memenuhi persyaratan yang ditentukan oleh Undang-undangan.

Itas diberikan kepada orang asing yang akan sekolah atau menempuh pendidikan di wilayah indonesia dengan visa Tinggal terbatas sesuai dengan peraturan pemerintah nomor 31 tahun 2013 pasal 102 tentang peraturan pelaksanaan Undang-undang nomor 6 tahun 2011 tentang keimigrasian, dan untuk masa berlakunya maksimal 2 tahun yang dapat di perpanjang sampai dengan 6 tahun, oleh sebab itu mahasiswa asing wajib memperpanjang itas apabila masih perlu watu untuk berada di wilayah indonesia

\section{Kewajiban dan Sanksi Penjamin Mahasiswa Asing}

a) Melaporkan setiap perubahan status sipil, status keimigrasian, dan alamat;

b) Membiayai pemulangan ke negara asal;

c) Penjamin yang memberikan keterangan tidak benar atau tidak memenuhi jaminannya dipidana penjara paling lama 5 tahun dan denda paling banyak Rp.500.000.000 (Lima Ratus Juta Rupiah).

\section{Tim Pengawas Orang Asing (TIMPORA)}

Untuk melakukan pengawasan keimigrasian terhadap kegiatan orang asing di wilayah Indonesia, Menteri membentuk Tim Pengawasan Orang Asing yang 
anggotanya terdiri atas badan atau instansi pemerintah terkait, baik pusat maupun di daerah.

Undang-Undang Nomor 6 Tahun 2011 mengamanatkan bahwa Tim Pengawasan Orang Asing terdiri dari bebagai unsur. Unsur-unsur Tim Pengawas Orang Asing terdiri dari :

1) Kementrian Hukum dan Hak Asasi Manusia (Ditjen Imigrasi, Kanwil Kemenkumham, Kantor Imigrasi;

2) Pemerintah Daerah (Kesbangpolinmas, Disnakertrans, Dinsos, Dishubkominfo, Disdukcapil masing-masing daerah;

3) Penegak Hukum (Polri dan Kejaksaan Agung);

4) Pengamanan Negara (TNI dan BIN);

5) Instansi Vertikal lainnya (Kemenlu, Kemenag, Kemendagri).

Tujuan pembentukan Tim Pengawasan Orang Asing ini tidak lain agar pengawasan orang asing dilakukan secara terkoordinasi.Tim Pengawasan Orang Asing dapat dibentuk di pusat dan daerah (provinsi, kabupaten/kota, atau kecamatan) yang beranggotakan perwakilan dari instansi dan atau lembaga pemerintahan baik pusat maupun daerah.

Tim Pengawasan Orang Asing tingkat pusat dibentuk dengan Keputusan Menteri yang diketuai oleh Menteri atau Pejabat Imigrasi yang ditunjuk. Tim Pengawasan Orang Asing tingkat provinsi dibentuk dengan keputusan Kepala Kantor Wilayah Kementrian Hukum dan Hak Asasi Manusia yang diketuai oleh kepala Devisi Keimigrasian Kantor Wilayah Kementrian Hukum dan Hak Asasi Manusia. Tim Pengawasan Orang Asing tingkat kabupaten atau kota dan kecamatan dibentuk dengan Keputusan Kepala Kantor Imigrasi yang di ketuai oleh Kepala Kantor Imigrasi.

Tim Pengawasan Orang Asing bertugas memberikan saran dan pertimbangan kepada instansi dan/atau lembaga pemerintahan terkait, mengenai hal yang berkaitan dangan pengawasan orang asing. Tim Pengawasan Orang Asing juga dapat melakukan operasi gabungan jika diperlukan, baik itu bersifat khusus maupun Insidental.

\section{Pelanggaran Izin tinggal Keimigrasian oleh Mahasiswa Asing di Indonesia}

Berdasarkan tindakan keimigrasian orang asing yang berada di wilayah Indonesia yang melakukan kegiatan yang berbahaya bagi keamanan dan ketertiban umum, atau tidak menghormati atau mentaati peraturan yang diatur dalam pasal 75 sampai dengan 80 undang-undang nomor 6 tahun 2011. Ketentuan pasal 75 ayat (1) menyatakan bahwa tindakan keimigrasian yang dilakukan terhadap orang asing yang berada di wilayah Indonesia yang melakukan kegiatan yang berbahaya bagi keamanan dan ketertiban umum, atau tidak menghormati atau menaati peraturan perundang-undangan yang berlaku.

\section{Sanksi Terhadap Pelanggar Izin Tinggal oleh Mahasiswa Asing di Indonesia.}

Pelanggaran atas ketentuan pasal di samping dapat dikenakan tindakan keimigrasian seperti diatas juga dapat dikenakan pasal 122 huruf (a) dengan 
pidana pidana penjara paling lama 5 (lima) tahun dan pidana denda paling banyak Rp 500.000.000 (lima ratus juta rupiah) karena menyalahgunakan atau melakukan kegiatan yang tidak sesuai dengan izin tinggal yang diberikan kepadanya . Lebih lanjut tentang penerapan sanksi pidana dalam tindakan pidana pelanggaran izin tinggal keimigrasian diatur dalam Keputusan Menteri Kehakiman RI nomor : M.02-PW.09.02 tahun 1995 tentang tata cara pengawasan, pengajuan keberatan orang asing dan tindakan keimigrasian, terutama pada Bab III, dengan sub judul tindakan justisial, pasal 16 sampai 18 yang pada pokoknya menetapkan hal-hal sebagai berikut :

a. Orang asing yang cukup bukti melakukan tindak pidana keimigrasian, dalam hal ini pelanggaran izin keimigrasian, diajukan kepengadilan;

b. Penyidikan, pemberkasan, penyampaikan perkara dilakukan sesuai dengan ketentuan Undang-undang nomor 8 tahun 1981 tentang hukum acara pidana.

c. Orang asing yang sedang dalam proses peradilan yang di ancam pidana keimigrasian kurang dari 5 tahun, dikenakan tindakan keimigrasian;

d. Orang asing diancam 5 tahun atau lebih ditempatkan dalam rumah tahanan negara;

e. Orang asing yang telah menjalankan hukuman dan belum dapat dipulangkan, dapat di tempatkan di karantina;

f. Orang asing yang telah selesai menjalani hukuman dapat dikeluarkan dari wilayah Indonesia.

\section{PENUTUP}

\section{Kesimpulan}

Berdasarkan uraian-uraian tersebut, dapat diambil beberapa kesimpulan, yaitu :

1. Pelaksanaan Undang-undang Republik Indonesia nomor 6 tahun 2011 tentang penyalahgunaan izin tinggal keimigrasian di Indonesia sudah berjalan dengan maksimal tetapi terdapat beberapa kendala yang terjadi dalam sistem pelaksanaan penyelesaian suatu masalah izin tinggal keimigrasian. dari pengamatan pada kasus-kasus yang ada, bahwa sanksi yang dijatuhkan oleh aparat penegak hukum dalam kasus tindak pidana penyalahgunaan izin tinggal keimigrasian adalah lebih bersifat non-pro justitia. Yang dapat tindakan keimigrasian yang salah satunya dilakukan deportasi. Hal ini dikarenakan mengingat adanya upaya banding, kasasi, atau grasi yang dimiliki oleh warga asing apabila ditempuh dengan cara pro justitia. Dalam hal ini pengawasan pelanggaran izin tinggal ada beberapa undang-undang yang mengatur seperti halnya undang-undang nomor 6 tahun 2011 dan peraturan pemerintah nomor 31 tahun 1994 tentang pengawasan orang asing, banyak aspek yang menunjang dalam pengawasan orang asing, namun harus ada pihak yang saling koordinasi antar instansi negara yang dapat membantu dalam pengawsan orang asing. Hal ini tentu saja membutuhkan biaya operasional yang cukup tinggi, mengingat dana operasional dari negara yang sangat terbatas. Karena menurut politis dan ekonomis cara tindakan keimigrasian dianggap lebih praktis dan efisien. Kecuali masalah penyalahgunaan izin tersebut menyangkut masalah peredaran narkoba, terorisme dan perdagangan manusia (human trafficking), 
maka jalan pro justitia yang harus ditempuh agar menimbulkan efek jera bagi warga asing yang melakukan tindak pidana di bidang keimigrasian.

2. Sanksi Pelanggaran izin tinggal di Indonesia ini diatur dalam undangundang nomor 6 tahun 2011 tentang keimigrasian, dimana banyak peraturan pemerintah, peraturan pelaksana, keputusan menteri, dan peraturan perundang-undangan yang menunjang. Dalam hal ini sanksi yang dikenakan harus diklasifikasikan sesuai dengan pelanggarannya, banyak sekali macam pelanggaran yang dapat terjadi pada orang asing, mulai dari tidak melaporkan data, penyalahgunaan izin tinggal, narkoba, teroris dan lain-lain.

\section{Saran}

Adapun saran yang dapat diberikan adalah sebagai berikut:

1. Pelaksanaan Undang-undang Republik Indonesia nomor 6 tahun 2011 tentang Keimigrasian di Indonesia seharusnya lebih di perhatikan tentang pengawasan orang asing yang datang di wilayah Indonesia agar tidak terjadi pelanggaran izin tinggal. Pengawasan yang lebih ketat dimulai pada saat pemberian visa, lebih diutamakan tujuan orang asing masuk ke Indonesia dengan jaminan apabila mereka melanggar izin tinggal akan dikenakan tindakan atau sanksi hukum sesuai dengan ketentuan yang ada, dalam pemberian tanda masuk bagi orang asing di tempat pemeriksaan imigrasi lebih teliti dalam proses pemeriksaan baik dokumen maupun visa yang ada, pengawasan di lapangan harus lebih memperhatikan tempattempat yang banyak ditinggali orang asing dan dilakukan pemeriksaan visa yang mereka gunakan saat tinggal di Indonesia.

yang terakhir lebih fokus pada kantor imigrasi bagi yang mengurus perpanjangan visa agar lebih berkoordinasi dengan Instansi terkait agar dapat dilakukan pemeriksaan yang berkaitan dengan tujuan/kegiatan yang dilakukan orang asing tersebut sehingga orang asing tersebut melakukan perpanjangan Izin Tinggal Keimigrasian. Perlu juga diadakan penindakan secara hukum bagi oknum petugas atau pejabat imigrasi yang ikut serta dalam membantu melakukan tindak pidana keimigrasian tersebut. Demikian juga yang tidak kalah penting petugas terkait dengan dilengkapi peralatan dan sistem yang mampu melakukan koordinat di titik-titik rawan orang asing yang tinggal di suatu wilayah lengkap dengan data diri, dokumen perjalanan yang digunakan disesuaikan dengan ketentuan yang telah ditetapkan.

Penegakan hukum yang berkaitan dengan keimigrasian ini tidak hanya memberikan sosialisasi terhadap orang asing atau mahasiswa asing, namun juga melibatkan setiap instansi terkait, penegak hukum juga harus diberikan sosialisasi juga mengenai mekanisme keimigrasian, dengan begitu semua instansi terkait dapat berkoordinasi atau bekerja sama dengan baik dalam rangka menciptakan kenyamanan dan keamanan negara.

Dalam pencegahan tindak pidana penyalahgunaan Izin tinggal Keimigrasian khususnya dengan melakukan cegah dan tangkal (cekal list) hendaknya mencerminkan prinsip-prinsip negara yang berdasarkan hukum, tidak berdasarkan kekuasaan belaka. Dan juga mengkoordinasikan tindakan cekal agar dapat dengan cepat dilaksanakan sebelum orang yang 
dimaksud tidak mengganggu ketertiban umum, bahaya negara dan melarikan diri.

2. Sanksi pidana seharusnya tidak hanya kuat pada sistem deportasi maupun kurungan penjara, mengingat biaya negara yang harus di keluarkan cukup besar dan di anggap menjadi beban negara, namun pemerintah Indonesia hendaknya lebih memperkuat sistem sanksi denda administratif, selain menguntungkan negara ini akan menjadikan efek jera dan berfungsi menutup biaya-biaya yang dikeluarkan oleh negara di bidang keimigrasian.

\section{DAFTAR PUSTAKA}

Ajad Sudrajad Havid, Formalitas Keimigrasian, Direktorat Jenderal Imigrasi Departemen Hukum dan HAM thn 2008

M.Imam Santoso, "Perspektif Imigrasi dalam Pembangunan Ekonomi dan Ketahanan Nasional”, UI Press Jakarta, 2004

Undang-undang Nomor 6 tahun 2011 tentang keimigrasian;

Peraturan pemerintah Nomor 38 tahun 2005 tentang visa, izin masuk dan, izin keimigrasian;

Peraturan Pemerintah Nomor 31 Tahun 1994 tentang Pengawasan Orang Asing; Peraturan pemerintah nomor 31 tahun 2013 tentang peraturan pelaksana Undangundang nomor 6 tahun 2011; 